\title{
The Effect of Rhenium Addition on Microstructure and Corrosion Resistance of Inconel 718 Processed by Selective Laser Melting
}

\author{
KAMIL MAJCHROWICZ, ZBIGNIEW PAKIEŁA, JANUSZ KAMIŃSKI, \\ MAGDALENA PŁOCIŃSKA, TOMASZ KURZYNOWSKI, and EDWARD CHLEBUS
}

\begin{abstract}
In this study, the effect of rhenium addition $(2,4$, and $6 \mathrm{wt}$ pct $)$ and building orientation $(0$ and $90 \mathrm{deg}$ ) on the microstructure and corrosion resistance of Inconel 718 (IN718) alloy processed by selective laser melting (SLM) was investigated. Microstructure characterization showed that the as-built IN718-Re alloys consist of columnar grains growing parallel to the building direction ( $Z$-axis). Each columnar grain was characterized by a fine columnar/cellular dendritic substructure with $\mathrm{Nb}$ - and Mo-rich Laves phases and MC-type carbides embedded in the interdendritic spaces. Rhenium addition segregated to $\gamma$ phase dendrites which resulted in an increase of the columnar/cellular substructures width with increasing Re content. Due to a strong microstructure anisotropy of SLM-processed IN718-Re alloys, the corrosion properties were examined for mutually perpendicular planes: XY (90 deg samples) and XZ (0 deg). The presence of rhenium enhanced the corrosion resistance of IN718 alloy in $0.1 \mathrm{M} \mathrm{Na}_{2} \mathrm{SO}_{4}$ and $\mathrm{NaCl}$ solutions at both exposed planes. The corrosion current density was significantly reduced for IN718-Re alloys and increasing Re content correlated with a more positive shift in corrosion potential. Moreover, the XY plane possessed better corrosion resistance than the $\mathrm{XZ}$ plane due to the higher fraction of laser overlapping areas observed for the $\mathrm{XZ}$ plane.
\end{abstract}

https://doi.org/10.1007/s11661-018-4926-3

(C) The Author(s) 2018

\section{INTRODUCTION}

SELECTIVE laser melting (SLM) is an additive manufacturing (AM) technique which enables the production of nearly fully dense 3D metal parts in a layer-by-layer fabrication process. Subsequent 50 - to $100-\mu \mathrm{m}$-thick powder layers are melted and consolidated by a focused laser beam to obtain a given computer-aided design (CAD) model. ${ }^{[1-4]}$ Such processing allows the direct manufacture of metal parts with complex geometries with little to no further machining. This significantly reduces the material waste and investment cost for machining tools. ${ }^{[5]}$

KAMIL MAJCHROWICZ, ZBIGNIEW PAKIEŁA, JANUSZ KAMIŃSKI and MAGDALENA PŁAOCIŃSKA are with the Faculty of Materials Science and Engineering, Warsaw University of Technology, WołAoska 141, 02-507 Warsaw, Poland. Contact e-mail: kamil.majchrowicz@wimpw.edu.pl TOMASZ KURZYNOWSKI and EDWARD CHLEB are with the Faculty of Mechanical Engineering, Centre for Advanced Manufacturing Technologies/Fraunhofer Project Center, Wrocław University of Science and Technology, Łukasiewicza 5, 50-371 Wrocław, Poland.

Manuscript submitted March 16, 2018.

Article published online September 20, 2018
For the above reasons, the aircraft industry has become increasingly interested in the fabrication of Ni-based components by SLM. Extensive work has thus been conducted in recent years on SLM-processed Inconel 718 (IN718). ${ }^{[6-17]}$ IN718 is a common Ni-based $(\mathrm{Ni}-\mathrm{Cr}-\mathrm{Fe})$ austenite $(\gamma)$ alloy that combines high strength at elevated temperatures up to $700{ }^{\circ} \mathrm{C}$ with excellent corrosion resistance. For these attributes, it is widely used for turbine engines or high-speed airframe parts in the aircraft industry as well as for valves, packers, or fasteners in the oil and gas industry. ${ }^{[18-20]}$ IN718 is an age-hardenable alloy strengthened by precipitates of $\gamma^{\prime}\left(\mathrm{Ni}_{3}(\mathrm{Al}, \mathrm{Ti})\right)$ and $\gamma^{\prime \prime}\left(\mathrm{Ni}_{3} \mathrm{Nb}\right)$ phases. However, some undesirable phases, i.e., $\mathrm{NbC}, \delta-\mathrm{Ni}{ }_{3} \mathrm{Nb}$ and Laves phase represented by $(\mathrm{Ni}, \mathrm{Cr}, \mathrm{Fe})(\mathrm{Nb}, \mathrm{Mo}, \mathrm{Ti})$, can be also formed in IN718 alloy which leads to a degradation of its ductility and creep properties. ${ }^{[8,18,19]}$

Rhenium, as a refractory metal with an excellent creep strength and resistance to a wide range of corrosive environments, ${ }^{[21]}$ is highly effective in modifying the properties of Ni-based superalloys. It has been shown that $\mathrm{Re}$ addition significantly improves their high-temperature durability by decreasing the creep deformation rate. ${ }^{[2,23]}$ This results from the fact that $\mathrm{Re}$ is a slow-diffusing element in nickel ${ }^{[24,25]}$ and has a strong tendency to segregate in the $\gamma$ matrix. ${ }^{[26-28]}$ During 
high-temperature exposure, Re tends to pile up at the $\gamma /$ $\gamma^{\prime}$ interface which leads to a reduced $\gamma^{\prime}$ coarsening rate ${ }^{[29,30]}$ and the retardation of the dislocation climb at the $\gamma / \gamma^{\prime}$ interface. ${ }^{[31]}$ Thereby, the creep resistance of Re-containing Ni-based superalloys is significantly enhanced. Recently, the effect of $\mathrm{Re}$ on mechanical properties has been also investigated in the case of SLM-processed Ni-based superalloys. Brynk et al. ${ }^{[10]}$ have found that $\mathrm{Re}$ addition reduces the fatigue crack growth rate of IN718 alloy fabricated by SLM, whereas its tensile strength at room temperature is only slightly increased and depends strongly on the building orientation of tensile samples.

On the contrary to the well-established effects of $\mathrm{Re}$ on the mechanical behavior of Ni-based alloys, the papers concerning its influence on corrosion properties are still limited. ${ }^{[32,33]}$ Amin et al. ${ }^{[32]}$ reported that the addition of 2.5 and $3.5 \mathrm{wt}$ pct Re increases the corrosion resistance of cast IN718 alloy in $1 \mathrm{M} \mathrm{Na} \mathrm{NO}_{4}+\mathrm{xM}$ $\mathrm{NaCl}$ solutions while an opposite trend is observed for higher Re content (6 wt pct). Also, Kurzynowski et al. ${ }^{[33]}$ investigated a IN718 laser surface alloyed with $\mathrm{Re}$ and found that dissolution of $14 \mathrm{wt}$ pet Re leads to a shift of corrosion potential to higher value and 24 pct reduction of corrosion current density in 3 wt pet $\mathrm{NaCl}$ solution. Alloying with $28 \mathrm{wt}$ pct of Re results in the presence of some undissolved Re particles in the processed layer on IN718 substrate which diminishes its corrosion resistance.

In order to explore the effect of $\mathrm{Re}$ addition on corrosion resistance of $\mathrm{Ni}$-based superalloys, this study was aimed at clarifying the electrochemical behavior of IN718 alloy with 2, 4, and 6 wt pct Re (named as IN718-2Re, IN718-4Re, and IN718-6Re) processed by SLM. Re has recently become one of the most expensive metals $^{[21]}$ and thus, its content in the investigated IN718-Re alloys was minimized to $2-6 \mathrm{wt}$ pet which is close to Re content in the second- and third-generation Ni-based superalloys (3 and 6 wt pct, respectively). ${ }^{[21,22,26]}$ Although SLM offers many advantages over conventional manufacturing technologies, a strong microstructure anisotropy can be observed in SLM parts due to the directional heat flux during laser beam fabrication. ${ }^{[34]}$ Therefore, IN718-Re alloys were manufactured at two building orientations to obtain a better understanding of the relation between $\mathrm{Re}$ content, microstructure, and corrosion resistance.

\section{MATERIAL AND METHODS}

Test specimens were fabricated using the SLM Realizer II 250 (MCP-HEK GmbH) from powder mixtures of commercially available IN718 (with the chemical composition of Ni-19.5Fe-18.37Cr-5.43Nb-3.27Mo-0.91Ti) and pure Re. The powders comprised mostly spherical particles having a good flowability. The mean diameter of $35 \pm 12$ and $20 \pm 12 \mu \mathrm{m}$ was determined for IN718 and Re powders, respectively, as measured using a Horiba LA-950 laser diffraction particle size analyzer. Milling was performed at a rotation speed of $200 \mathrm{rpm}$ in an uni-ball mill with a
$\mathrm{ZrO}_{2}$ container of $500 \mathrm{~mL}$ capacity filled with 25 balls of $25 \mathrm{~mm}$ diameter.

Cylindrical specimens with a diameter of $8 \mathrm{~mm}$ were manufactured at two building orientations with the cylinder axis perpendicular (herein referred to as $0 \mathrm{deg}$ ) and parallel $(90 \mathrm{deg})$ to the building direction (Figure 1). The XY scanning strategy (consecutive layers scanned twice in mutually perpendicular directions according to a zigzag pattern) was used for specimen preparation with following process parameters: laser power $400 \mathrm{~W}$, scanning speed $500 \mathrm{~mm} \mathrm{~s}^{-1}$, layer thickness $50 \mu \mathrm{m}$, and distance between scanning lines (hatch spacing) $160 \mu \mathrm{m}$. The chemical composition of the resulting SLM-processed IN718-Re alloys measured by an X-ray fluorescence (XRF) analyzer (Olympus Delta Professional) is presented in Table I.

Microstructure was examined with a Nikon Eclipse MA200 optical microscope (OM) and a Hitachi SU8000 scanning electron microscope (SEM) equipped with a backscattered electron (BSE) detector. Sections for metallographic observations were ground, polished, and etched for a few seconds using a solution of $20 \mathrm{~mL} \mathrm{HCl}$, $10 \mathrm{~g} \mathrm{FeCl}_{3}$, and $30 \mathrm{~mL}$ ethanol. The energy dispersive X-ray spectroscopy (EDS) analysis of samples and detailed precipitates characterization were carried out on a high-resolution scanning transmission electron microscope (STEM) Hitachi HD-2700. Thin lamellas for STEM investigation were prepared by focused ion beam (FIB) lift-out technique using a FIB-SEM Hitachi NB5000 system.

The corrosion resistance was examined at room temperature by the potentiodynamic polarization and electrochemical impedance spectroscopy (EIS) methods. The two testing environments were $0.1 \mathrm{M} \mathrm{Na}_{2} \mathrm{SO}_{4}$ and $0.1 \mathrm{M} \mathrm{NaCl}$ solutions, both acidified to $\mathrm{pH} 4$ by adding $\mathrm{H}_{2} \mathrm{SO}_{4}$ and $\mathrm{HCl}$, respectively. The specimens for corrosion tests were obtained by slicing SLM manufactured cylinders 0 and 90 deg to 1 -mm-thick discs. The exposed

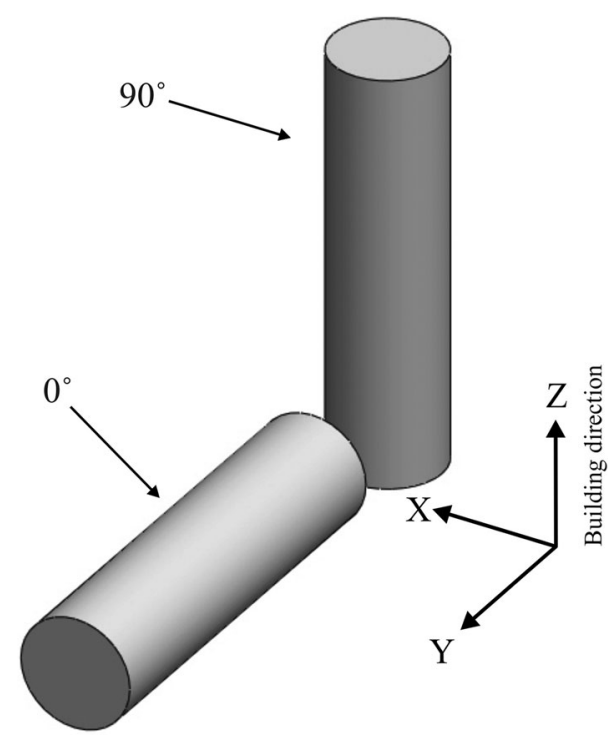

Fig. 1-Building orientation of cylindrical specimens manufactured by SLM. 
Table I. Chemical Composition (in Weight Percent) of IN718-Re Alloys Processed by SLM

\begin{tabular}{|c|c|c|c|c|c|c|c|c|}
\hline Material & $\mathrm{Ni}$ & $\mathrm{Fe}$ & $\mathrm{Cr}$ & $\mathrm{Nb}$ & Mo & $\mathrm{Ti}$ & $\operatorname{Re}$ & Other \\
\hline IN718 & 51.98 & 19.54 & 18.69 & 5.03 & 3.03 & 1.01 & - & 0.72 \\
\hline IN718-2Re & 50.97 & 18.99 & 17.77 & 4.80 & 2.87 & 1.16 & 2.16 & 1.28 \\
\hline IN718-4Re & 49.66 & 18.95 & 17.23 & 4.78 & 2.96 & 1.02 & 4.23 & 1.17 \\
\hline IN718-6Re & 48.26 & 18.73 & 17.25 & 4.44 & 2.69 & 0.90 & 6.52 & 1.21 \\
\hline
\end{tabular}

area of these $\sim 0.5 \mathrm{~cm}^{2}$ discs corresponded to $\mathrm{XZ}$ and $\mathrm{XY}$ planes, respectively. Before exposure, all surfaces were ground with $\mathrm{SiC}$ papers down to 1200 grit and cleaned ultrasonically in acetone. The potentiodynamic and impedance tests were conducted in a three-electrode setup (consisting of tested sample, saturated calomel electrode (SCE), and auxiliary platinum electrode) using an AutoLab PGSTAT100 potentiostat. The potentiodynamic curves were recorded from the potential of approximately $150 \mathrm{mV}$ below the corrosion potential $\left(E_{\text {corr }}-150 \mathrm{mV}\right)$ to $1500 \mathrm{mV}$ at a potential scan rate of $0.2 \mathrm{mV} \mathrm{s}^{-1}$. Corroded specimens were then investigated by SEM. Impedance tests were carried out in the frequency range from $10^{5}$ to $10^{-3} \mathrm{~Hz}$ at a sinusoidal signal amplitude of $5 \mathrm{mV}$. The impedance spectra were recorded in the potentiostatic mode at open circuit potential $\left(E_{O C P}\right)$ and, subsequently, analyzed by Boukamp's Equivert software.

\section{RESULTS AND DISCUSSION}

\section{A. Microstructure of IN718}

The microstructure of as-built IN718 samples is shown in Figure 2, in mutually perpendicular planes XY and XZ. A typical microstructure for SLM-processed materials with laminar structure and columnar architecture is observed. Considering the XY plane, the laser scan tracks with a width of about $150 \mu \mathrm{m}$ are clearly visible (Figures 2(a) and (b)). The parallel scan tracks are oriented in a zigzag pattern resulting from the building strategy and their width corresponds to the applied hatch spacing of $160 \mu \mathrm{m}$. A similar effect was observed in the literature. ${ }^{[6,7,13]}$ The individual tracks consist of elongated grains which are mutually parallel. Also, equiaxed grains with a size of 10 to $30 \mu \mathrm{m}$ can be recognized between neighboring scan tracks (Figure 2(c)). This is likely caused by a re-melting process in the overlapping areas. ${ }^{[7,13]}$ SEM observations in the XZ plane also reveal that the microstructure of as-built samples is dominated by columnar grains with a width of 10 to $30 \mu \mathrm{m}$ and a length of several hundred microns (Figures 2(d) and (e)) which are elongated along the building direction ( $Z$-axis). The individual columns are created by solid solution $\gamma$ phase which has been shown previously in References 6, 7 and 10 . Moreover, the arc-shaped melt pools can be noticed in the XZ plane (Figure 2(d)) which demonstrates the development of layers during laser beam manufacturing.
The melt pool size is determined by the applied layer thickness $(50 \mu \mathrm{m})$ and hatch spacing $(160 \mu \mathrm{m})$.

The observed unidirectional columnar grains which are longer than the thickness of scanned layers are a result of epitaxial grain growth occurring during SLM processing in the direction determined by heat flux. ${ }^{[11,35]}$ Since the heat dissipates mostly in the building direction (negative $Z$-direction), the highest temperature gradient and solidification rate appear along the $Z$-axis. Such processing conditions cause formation of fine columnar/cellular dendritic substructure in the as-built IN718. Each grain consists of columnar/cellular dendrites which are visible as equiaxed cellular structures in the XY plane (see the inset in Figure 2(c)) and columnar/cellular dendrites growing nearly parallel to the building direction in the XZ plane (Figure 2(f)). The typical width of the cellular and columnar structures is about the same and lies in the range between 700 and $1100 \mathrm{~nm}$. It should be mentioned that such fine dendritic substructure is a standard in the case of SLM-processed IN718 alloy. ${ }^{[6,11-14]}$

As suggested by Tucho et al., ${ }^{[8]}$ the formation of a columnar/cellular dendritic substructure seems to be accompanied by microsegregation. SLM processing characterized by a high solidification rate of the molten pool prevents macrosegregation of alloying elements with high susceptibility to segregation, i.e., Nb or Mo. However, it is not possible to completely avoid microsegregation of such elements. ${ }^{[6,36]}$ Figure 3 presents the EDS analysis results of as-built IN718 sample. The interdendritic regions are highly enriched in $\mathrm{Nb}$ and Mo which leads to formation of irregularly shaped Laves phases (with a size of about $1 \mu \mathrm{m}$ ) and MC-type carbides between dendritic cells. Moreover, the spherical $\mathrm{MC}$-type carbides rich in $\mathrm{Nb}$ and $\mathrm{Ti}$ with a size less than $100 \mathrm{~nm}$ can be also recognized in the matrix as well as a few fine Al oxides. The occurrence of Laves phase and MC-type carbides in the interdendritic spaces can be explained based on phase transformation sequence of IN718 alloy during cooling. The solidification process in IN718 alloy starts with liquid (L) phase to austenite matrix $\gamma$ phase reaction $(\mathrm{L} \rightarrow \gamma)$. Then, it is followed by the enrichment of interdendritic liquid in $\mathrm{Nb}$, Mo, Ti, and $\mathrm{C}$ and a sequence of eutectic-type reactions. As temperature decreases, the eutectic-type reaction $\mathrm{L} \rightarrow(\gamma+\mathrm{NbC})$ occurs causing depletion of the remaining liquid in $\mathrm{C}$. Afterwards, the concentration of $\mathrm{Nb}$ and Mo in the remaining liquid is sufficiently high and a second eutectic-type reaction $\mathrm{L} \rightarrow(\gamma+$ Laves $)$ leads to Laves phase formation. ${ }^{\text {[37-39] }}$ 


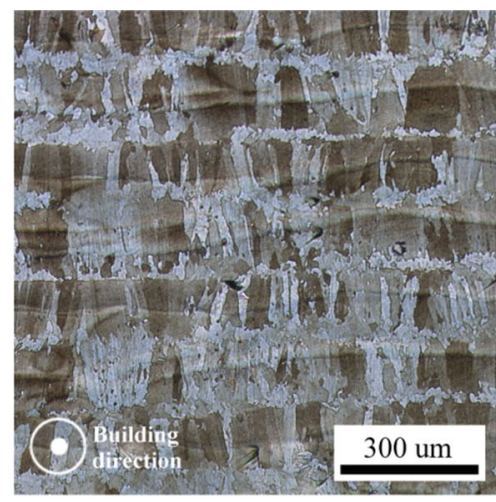

(a)

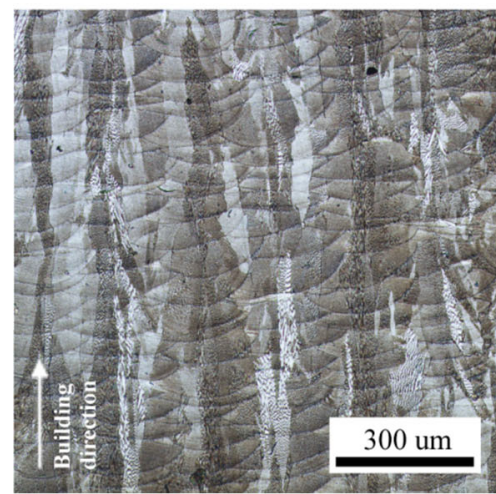

(d)

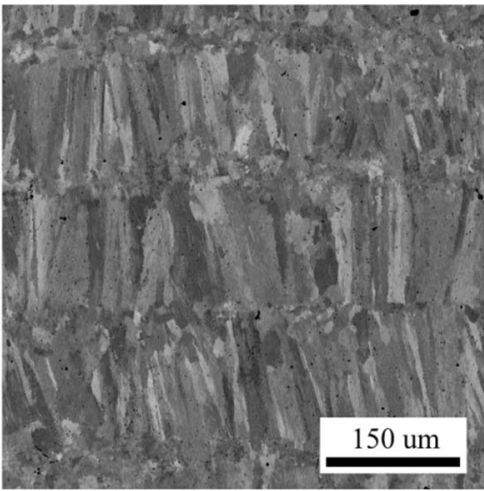

(b)

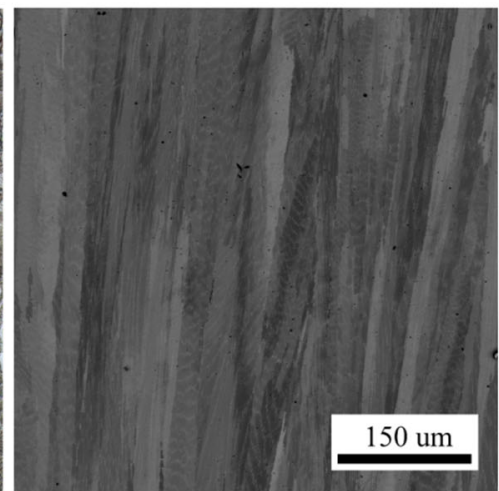

(e)

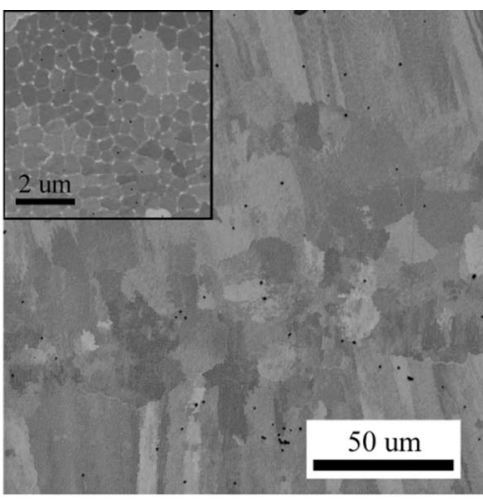

(c)

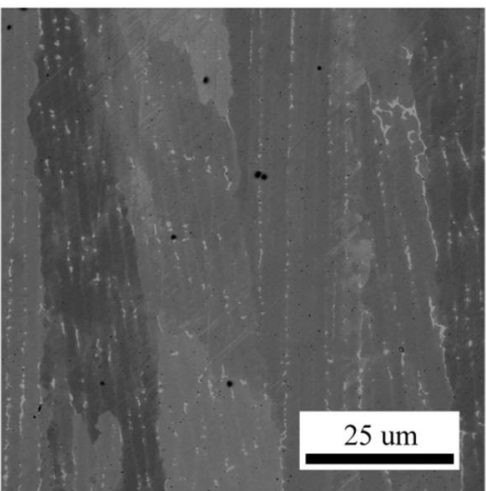

(f)

Fig. 2-Microstructure of as-built IN718 samples: $(a, b)$ in the XY plane showing laser scan tracks consisting of mutually parallel elongated grains and $(c)$ fine equiaxed grains in the overlapping areas; $(d, e)$ in the $\mathrm{XZ}$ plane showing arc-shaped melt pools and columnar grains growing parallel to the building direction. Fine cellular/columnar dendritic substructure is presented in (c) (see inset) and $(f)$.
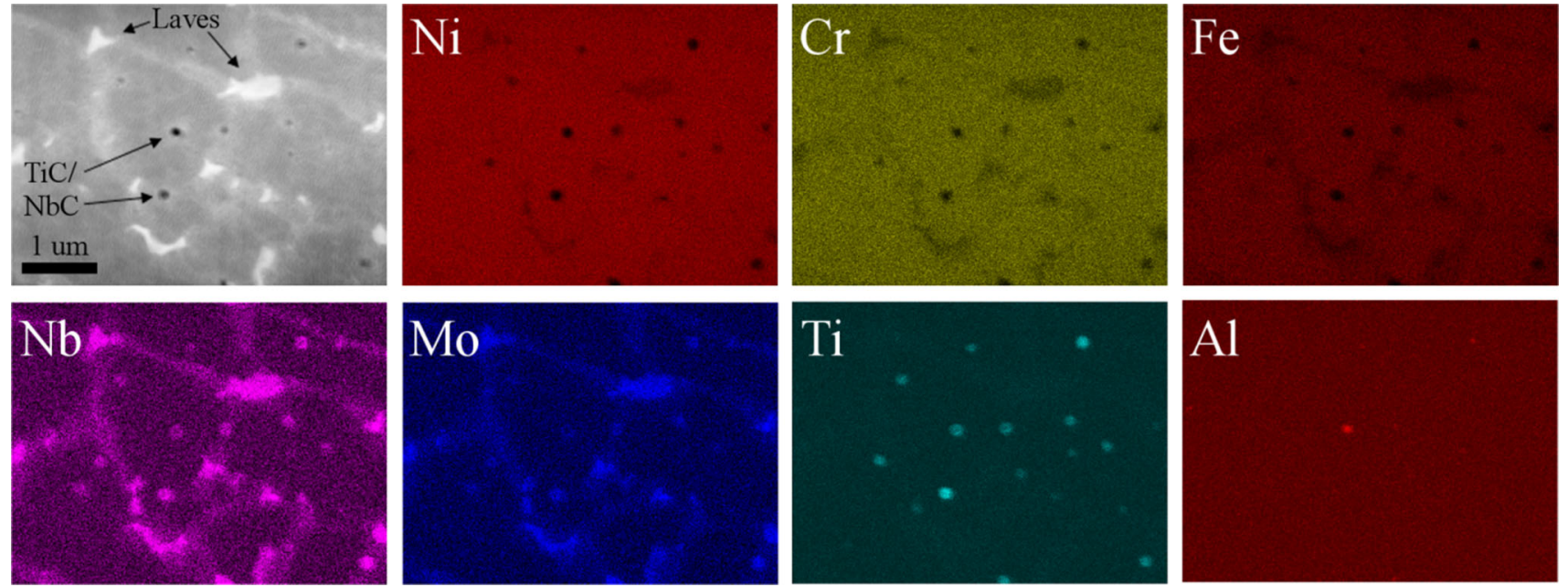

Fig. 3-EDS mapping analysis of as-built IN718 sample (XY plane).

\section{B. Microstructure of IN718-Re Alloys}

The addition of rhenium does not cause any drastic changes in the microstructure of SLM-processed IN718 alloy. The columnar architecture with fine dendritic substructure is still maintained in the case of IN718-Re alloys. The spherical MC-type carbides as well as Laves

phases in the interdendritic spaces enriched in $\mathrm{Nb}$ and Mo are also present in the IN718-Re alloys as shown in Figure 4. Rhenium has dissolved mostly in the $\gamma$ phase matrix (Figure 4(b)). However, some undissolved Re particles with a size ranging from several microns to $20 \mu \mathrm{m}$ can be also seen (Figure 4(a)). 


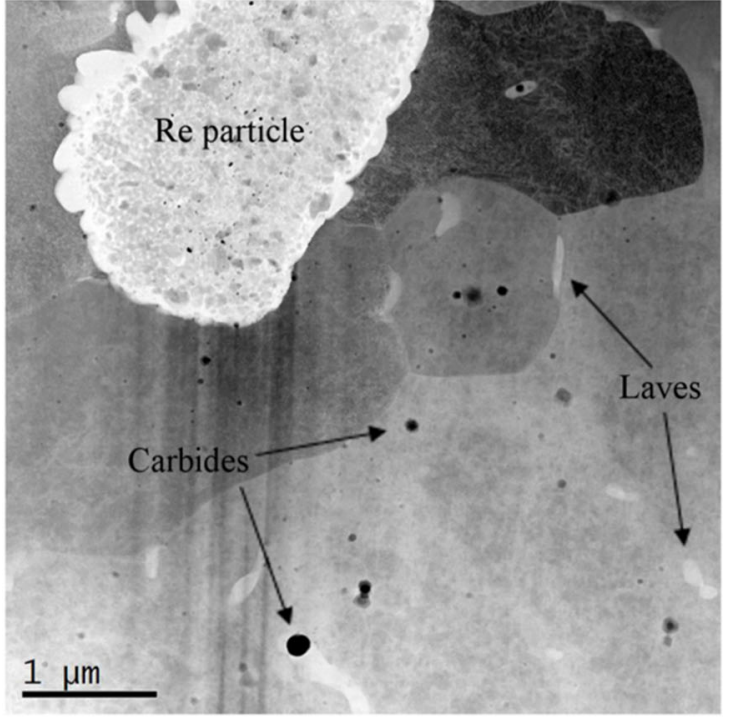

(a)

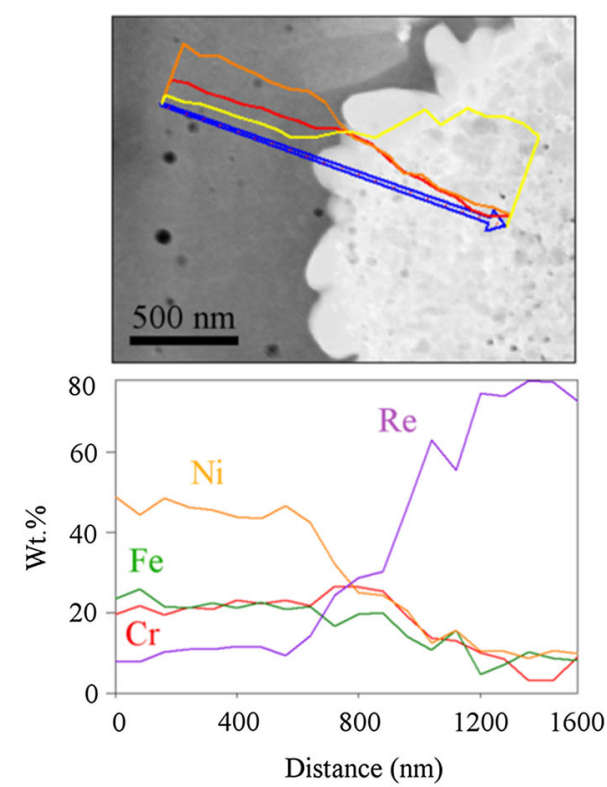

(b)

Fig. 4-Microstructure of IN718-6Re alloy in the XZ plane: (a) TEM micrograph showing the presence of Laves phase, carbides, and undissolved rhenium particle; $(b)$ chemical composition profile acquired across $\gamma$ phase matrix-Re particle interface.

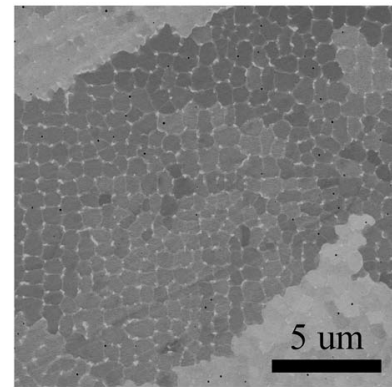

(a)

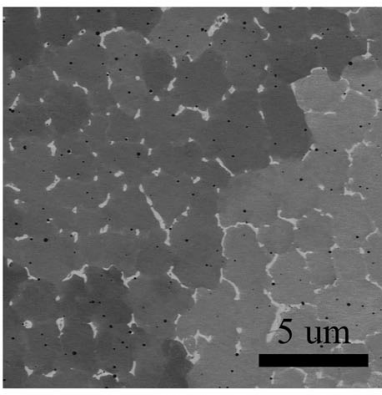

(c)

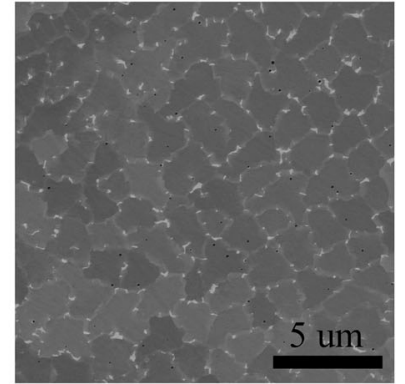

(b)

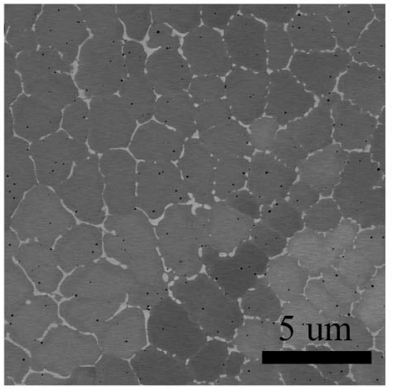

(d)

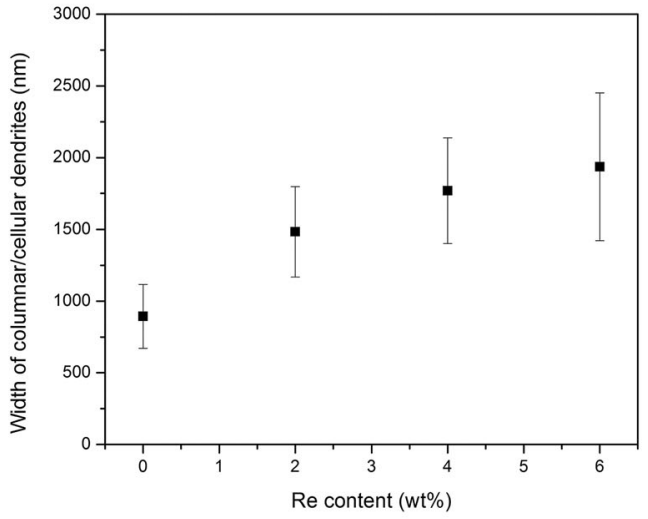

(e)

Fig. 5-The dendritic substructure within individual grains of (a) IN718, (b) IN718-2Re, (c) IN718-4Re, and (d) IN718-6Re alloys in the XY plane with (e) plot summarizing the effect of Re content on the width of columnar/cellular dendrites.

The main microstructural change due to the presence of $\operatorname{Re}$ atoms in the $\gamma$ phase matrix is the size of columnar/cellular dendrites. The width of columnar/cellular structures increases with increasing $\mathrm{Re}$ content (Figure 5) from $893 \pm 223$ to $1936 \pm 515 \mathrm{~nm}$ observed for IN718 and IN718-6Re, respectively. A similar effect of Re addition was observed by El-Bagoury et al. ${ }^{[40]}$ for cast IN718 alloy. Higher Re content resulted in the increased volume fraction of $\gamma$ phase and enlarged dendrite arm spacing. Such microstructural change can be explained by the redistribution of alloying elements. Rhenium is known as a solid solution strengthener in Ni-based alloys ${ }^{[26,27]}$ and tends to segregate to $\gamma$ dendrites. ${ }^{[28,41]}$ As a result, the volume fraction of $\gamma$ phase 
columnar/cellular dendrites increases with higher $\mathrm{Re}$ content at the expense of interdendritic regions enriched in $\mathrm{Nb}$ and Mo.

El-Bagoury et al. ${ }^{[40]}$ have also shown that the enlarged dendrite arm spacing in Re-modified IN718 alloy is observed for a wide range of cooling rates during the solidification process (from 1 to $100 \mathrm{~K} \mathrm{~min}^{-1}$ ). The relation between dendrite arm spacing $d$ (expressed in $\mu \mathrm{m}$ ) and cooling rate $V$ (expressed in $\mathrm{K} \mathrm{min}^{-1}$ ) for Re-free IN718 and IN718 alloy with 3.5 wt pct Re addition, respectively, can be given as ${ }^{[40]}$

$$
\begin{aligned}
& d=142.9 \cdot V^{-0.33} \\
& d=145.5 \cdot V^{-0.30} .
\end{aligned}
$$

The cooling rate of about $10^{5} \mathrm{~K} \mathrm{~s}^{-1}$ is reported for SLM manufacturing ${ }^{[9,42,43]}$ which is a few orders of magnitude higher than for traditional casting (0.01-0.33 $\left.\mathrm{K} \mathrm{s}^{-1[9]}\right)$. Considering this value of cooling rate and Eqs. [1] and [2], the following size of dendrites can be expected: $830 \mathrm{~nm}$ for SLM-processed Re-free IN718 and $1350 \mathrm{~nm}$ for Re-modified IN718 alloy. These values are in good agreement with the average size of dendrites obtained in this paper (Figure 5(e)) which suggests that the formation of such fine dendritic substructure results mainly from the extreme solidification conditions. Moreover, it has been shown that at high cooling rates the primary dendrite shape is altered to a more equiaxed cell-like form $^{[36]}$ and thus, in the SLM process, cellular or mixed columnar/cellular dendritic substructure is formed $^{[43,44]}$ as shown in the current work (Figures 2 and 5).

\section{Corrosion Resistance}

\section{Potentiodynamic polarization}

In order to observe the effect of rhenium addition on the corrosion resistance of IN718 alloy, potentiodynamic polarization measurements were conducted in 0.1 $\mathrm{M} \mathrm{Na}_{2} \mathrm{SO}_{4}$ and $0.1 \mathrm{M} \mathrm{NaCl}$ solutions (both acidified to $\mathrm{pH}$ 4). All electrochemical parameters for IN718-Re alloys manufactured at two building directions, i.e., 0 and $90 \mathrm{deg}$, are listed in Table II.

Figure 6(a) presents polarization curves for IN718-Re alloys manufactured at $0 \mathrm{deg}$, in a $0.1 \mathrm{M} \mathrm{Na} \mathrm{Na}_{4}$ environment. The passive and transpassive regions can be noticed according to the current response. IN718 alloy is in the passive state within a wide range of potentials with a passivation plateau observed between 0 and $700 \mathrm{mV}$. The transpassive region is visible as a rapid increase in the current density of around $1000 \mathrm{mV}$ corresponding to the dissolution of chromium compounds (the change of oxidation state from $\mathrm{Cr}^{3+}$ to $\left.\mathrm{Cr}^{6+}\right)$. Further anodic polarization above $1000 \mathrm{mV}$ leads to a degradation of passive film, and to a thick and cracked chromium-based oxide layer.

The electrochemical behavior as well as corrosion current density $i_{\text {corr }}$ and corrosion potential $E_{\text {corr }}$ of IN718-Re alloys (0 deg) differ slightly from Re-free IN718 (Figure 6(a) and Table II). One of the differences is lower current density in the cathodic branch and in the active-passive domain for IN718-Re alloys which suggest easier reduction of the air-formed passive film on the IN718 alloy. On the other hand, the addition of rhenium reduced passive layer durability, as demonstrated by a shortened passivation plateau (up to 500 $\mathrm{mV}$ ) and a shift of polarization curves within the range of 500 to $900 \mathrm{mV}$ to lower potential values. It should be also noticed that the curves are shifted further for higher Re content. Nevertheless, the major differences between IN718 and IN718-Re alloys are $i_{\text {corr }}$ and $E_{\text {corr }}$ values (Table II). The addition of Re results in the enhanced corrosion resistance of IN718 alloy. The corrosion current density $i_{\text {corr }}$ is reduced significantly from 0.20 to $0.07-0.09 \mu \mathrm{A} \mathrm{cm}{ }^{-2}$ observed for IN718 and IN718-Re alloys, respectively. Moreover, the corrosion potential $E_{\text {corr }}$ is shifted to positive values with increasing $\mathrm{Re}$ content. The overall increase of its value for IN718-6Re alloy is about $60 \mathrm{mV}$ (from -110 to $-50 \mathrm{mV}$ observed for IN718 and IN718-6Re, respectively).

Building orientation of 0 and $90 \mathrm{deg}$ yielded similar electrochemical behavior and corrosion resistance (Figures 6(a) and (b)). The corrosion current density $i_{\text {corr }}$ values are slightly reduced for $90 \mathrm{deg}$ samples, whereas 0 deg samples (expect of IN718-6Re) exhibit a more positive $E_{\text {corr }}$ (Table II). Even so, the positive effect of rhenium addition on corrosion resistance of IN718 alloy is still observed as the corrosion potential $E_{\text {corr }}$ increases with increasing Re content.

The results of potentiodynamic measurements in a chloride containing environment $(0.1 \mathrm{M} \mathrm{NaCl}, \mathrm{pH} 4)$ also exhibit the enhanced corrosion resistance of IN718-Re alloys in comparison to Re-free IN718 alloy (Figures 6(c) and (d) and Table II). The corrosion current density $i_{\text {corr }}$ is significantly reduced and corrosion potential $E_{\text {corr }}$ is shifted to more positive values for IN718-Re alloys. Samples manufactured at 0 and $90 \mathrm{deg}$ show similar corrosion resistance. Moreover, the addition of Re stabilizes the passive layer in $\mathrm{Cl}^{-}$containing environment. This is demonstrated by the presence of sharp current density spikes within the potential range of 300 to $600 \mathrm{mV}$ for IN718 and IN718-2Re alloys (Figure 6(c)). Such current density spikes correspond to a metastable pit growth ${ }^{[45,46]}$ and do not occur for IN718-4Re and IN718-6Re alloys.

Figure 7 presents SEM images of IN718 samples manufactured at two building orientations 0 and $90 \mathrm{deg}$ after potentiodynamic polarization to around $1000 \mathrm{mV}$ in $0.1 \mathrm{M} \mathrm{NaCl}$ solution ( $\mathrm{pH} 4)$. In the case of the $0 \mathrm{deg}$ sample, the whole exposed surface has been etched showing the initial microstructure elements, i.e., the arc-shaped melt pools (Figure 7(a)) and fine columnar/cellular dendritic substructure (Figure 7(c)). On the contrary, SEM observations of sample 90 deg revealed that the sample's surface is locally corroded (Figure 7(b)). The thicker oxide layer is formed within the mutually parallel bands separated by approx. $150 \mu \mathrm{m}$ from each other which correspond to the overlapping areas between adjacent laser scan tracks. Meanwhile, the thinner oxide layer with still visible grinding scratches is present between the overlapping areas (Figure $7(d)$ ). It should be noted that the current 
Table II. Potentiodynamic Test Results of IN718-Re Alloys Manufactured at Two Building Orientations 0 and 90 deg Exposed in $0.1 \mathrm{M} \mathrm{Na}_{2} \mathrm{SO}_{4}$ and $0.1 \mathrm{M} \mathrm{NaCl}$ Solutions (pH 4)

\begin{tabular}{|c|c|c|c|c|c|}
\hline \multirow[b]{3}{*}{ Environment } & \multirow[b]{3}{*}{ Material } & \multicolumn{4}{|c|}{ Building Orientation } \\
\hline & & \multicolumn{2}{|c|}{$0 \mathrm{deg}$} & \multicolumn{2}{|c|}{$90 \mathrm{deg}$} \\
\hline & & $i_{\text {corr }}\left(\mu \mathrm{A} \mathrm{cm}^{-2}\right)$ & $E_{\text {corr }}(\mathrm{mV})$ & $i_{\text {corr }}\left(\mu \mathrm{A} \mathrm{cm}^{-2}\right)$ & $E_{\text {corr }}(\mathrm{mV})$ \\
\hline \multirow[t]{4}{*}{$0.1 \mathrm{M} \mathrm{Na}_{2} \mathrm{SO}_{4}(\mathrm{pH} 4)$} & IN718 & 0.200 & -110 & 0.091 & -160 \\
\hline & IN718-2Re & 0.070 & -105 & 0.093 & -140 \\
\hline & IN718-4Re & 0.090 & -70 & 0.053 & -100 \\
\hline & IN718-6Re & 0.080 & -50 & 0.051 & -50 \\
\hline \multirow[t]{4}{*}{$0.1 \mathrm{M} \mathrm{NaCl}(\mathrm{pH} 4)$} & IN718 & 0.150 & -200 & 0.106 & -195 \\
\hline & IN718-2Re & 0.018 & -125 & 0.048 & -110 \\
\hline & IN718-4Re & 0.029 & -80 & 0.027 & -125 \\
\hline & IN718-6Re & 0.025 & -103 & 0.017 & -85 \\
\hline
\end{tabular}

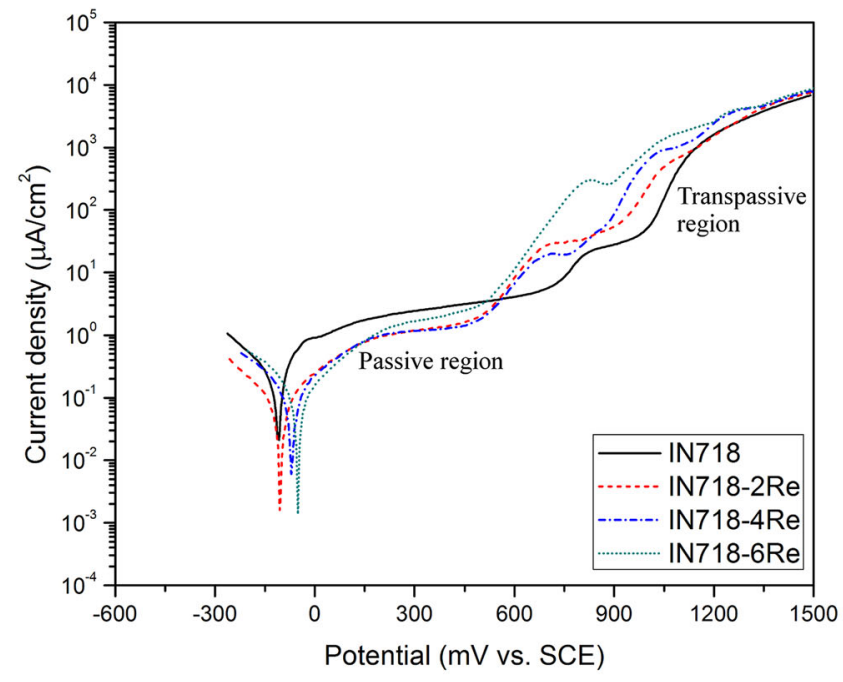

(a)

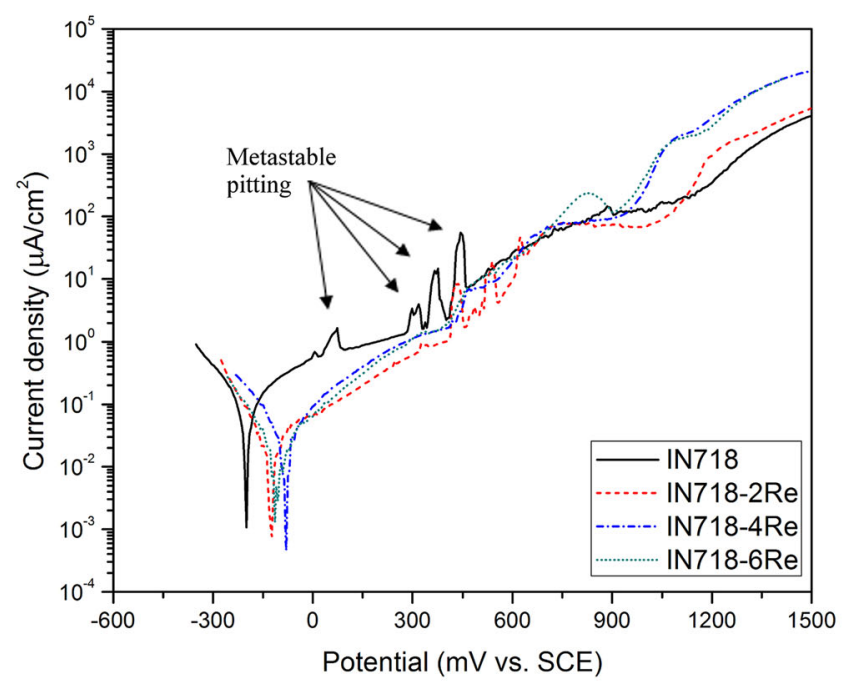

(c)

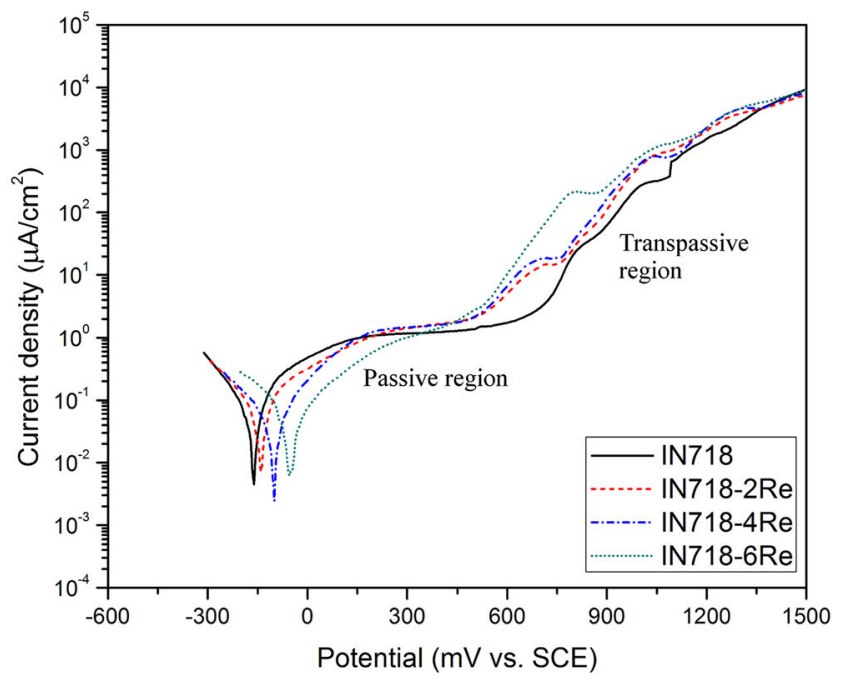

(b)

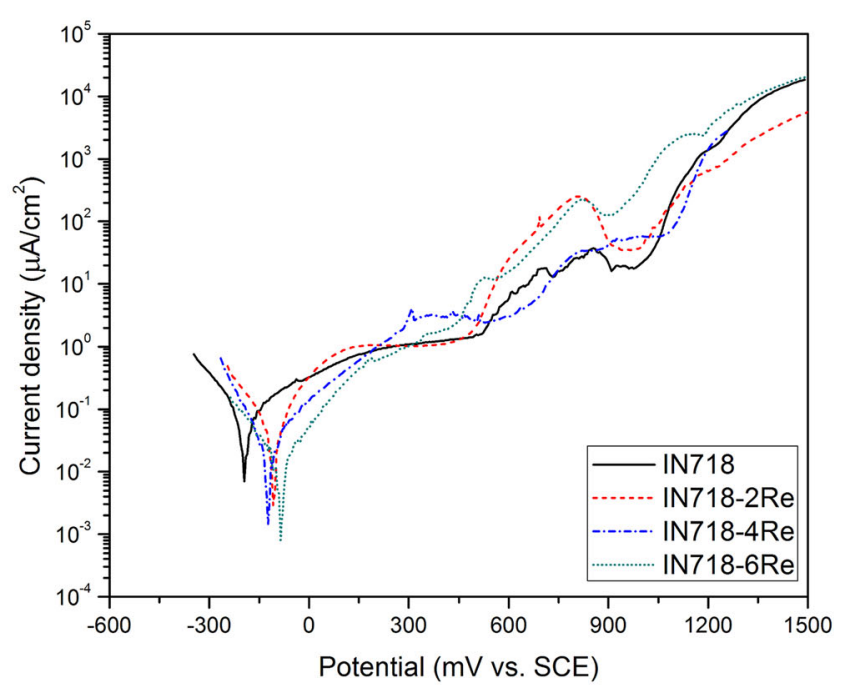

(d)

Fig. 6-Potentiodynamic polarization curves of IN718-Re alloys by building orientation and solution: (a) 0 deg in $0.1 \mathrm{M} \mathrm{Na}_{2} \mathrm{SO}_{4},(b) 90$ deg in $0.1 \mathrm{M} \mathrm{Na}_{2} \mathrm{SO}_{4},(c) 0$ deg in $0.1 \mathrm{M} \mathrm{NaCl}$, and $($ d $) 90$ deg in $0.1 \mathrm{M} \mathrm{NaCl}$. For all solutions, pH 4. 


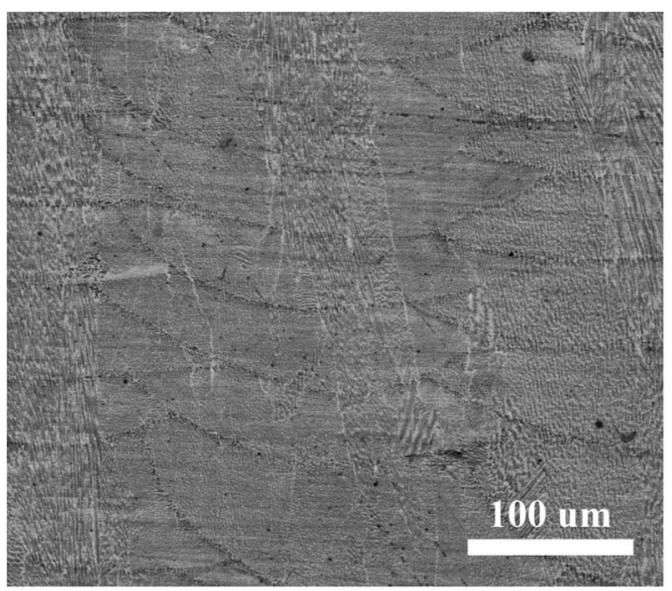

(a)

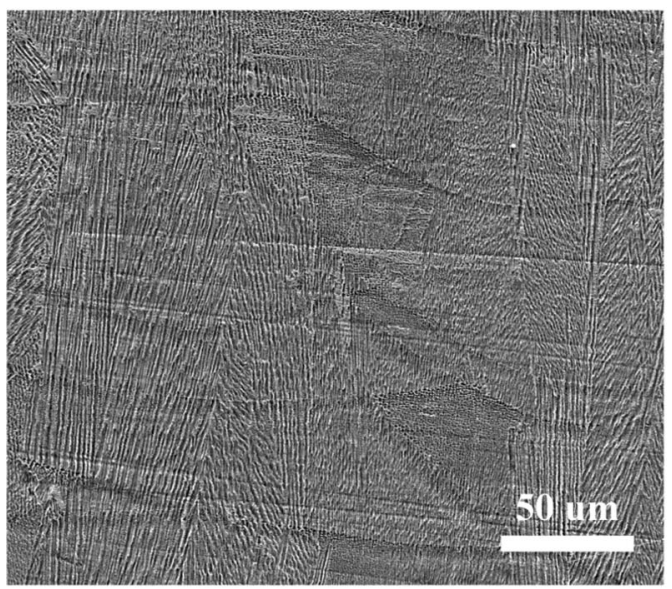

(c)

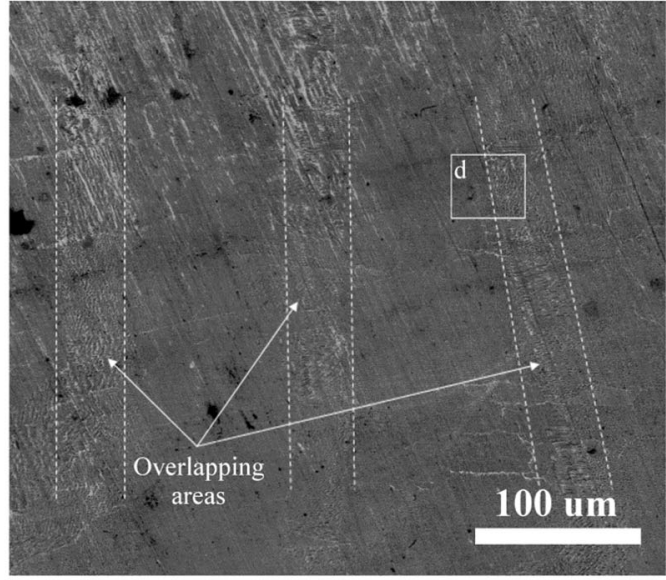

(b)

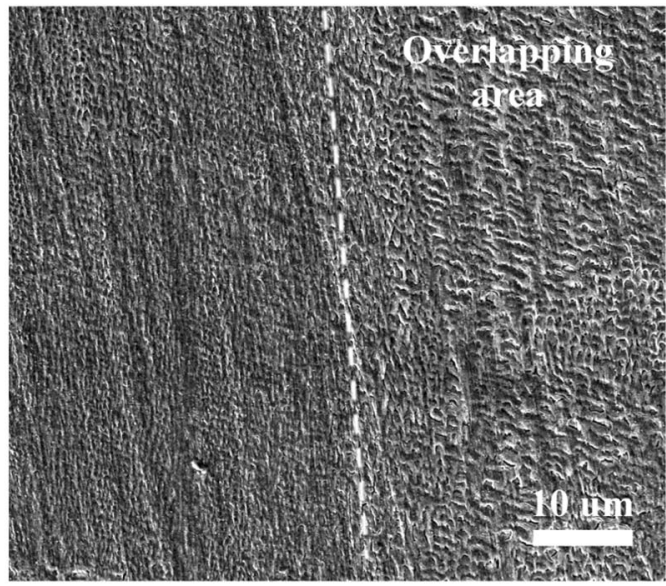

(d)

Fig. 7-SEM images of IN718 alloy manufactured at $(a, c) 0$ deg and $(b, d) 90$ deg after electrochemical polarization to around $1000 \mathrm{mV}$ in 0.1 $\mathrm{M} \mathrm{NaCl}$ solution ( $\mathrm{pH} 4)$.

density for potential of $1000 \mathrm{mV}$ for sample 0 deg is almost one order of magnitude higher than for sample $90 \mathrm{deg}$. Therefore, considering the potentiodynamic polarization measurements and SEM observation results, the overlapping areas seem to be the preferential sites for corrosion of SLM-processed IN718-Re alloys. This may result from the fact that the overlapping areas are characterized by the higher fraction of grain boundaries (Figure 2) and higher accumulated energy. Further electrochemical corrosion leads to the formation of a uniform oxide layer on the sample's surface and the revealing of the initial microstructure elements resulting from the laser beam manufacturing such as the arc-shaped melt pools or laser scan tracks.

\section{EIS measurements}

The potentiodynamic polarization tests showed that IN718-Re samples manufactured at 90 deg have slightly higher corrosion resistance (lower corrosion current density $i_{\text {corr }}$ ) than samples 0 deg in the $\mathrm{Na}_{2} \mathrm{SO}_{4}$ environment. To investigate the effect of building orientation and $\mathrm{Re}$ addition on the electrochemical behavior more precisely, EIS measurements were performed for
IN718 and IN718-6Re alloys fabricated at 0 and 90 deg in $0.1 \mathrm{M} \mathrm{Na}_{2} \mathrm{SO}_{4}$ solution ( $\left.\mathrm{pH} 4\right)$.

The equivalent electrical circuit (EC) used to fit the experimental data is presented as an inset in Figure 8(a). It is a model commonly used for a locally corroded systems which provides the best fit with the smallest error. ${ }^{[47,48]}$ In the present study, circuit elements in this model are as follows: $R_{\mathrm{S}}$ corresponds to the electrolyte resistance; $C P E_{1}$ and $R_{1}$ are constant phase element (CPE) and resistance, respectively, representing the capacitance and resistance of the passive film formed on the substrate surface; $C P E_{2}$ and $R_{2}$ are associated with processes occurring within the overlapping areas.

Figure 8 depicts the Nyquist and Bode plots for IN718 and IN718-6Re alloys fabricated at 0 and 90 deg in the acidified $0.1 \mathrm{M} \mathrm{Na} \mathrm{NO}_{4}$ at the $E_{O C P}$ of each sample. The fitted impedance parameters for all tested samples are summarized in Table III. The Nyquist plot (Figure 8(a)) shows the significantly higher impedance of samples manufactured at $90 \mathrm{deg}$ in comparison to those fabricated at $0 \mathrm{deg}$. Also, the enhanced impedance of IN718-6Re is observed at both building orientations. From the Bode plot (Figure 8(b)), the occurrence of two 


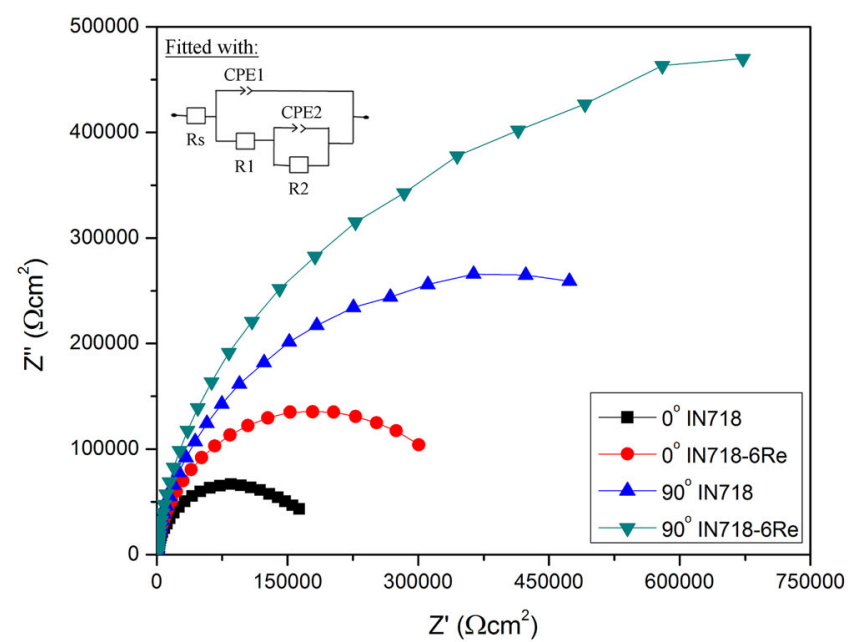

(a)

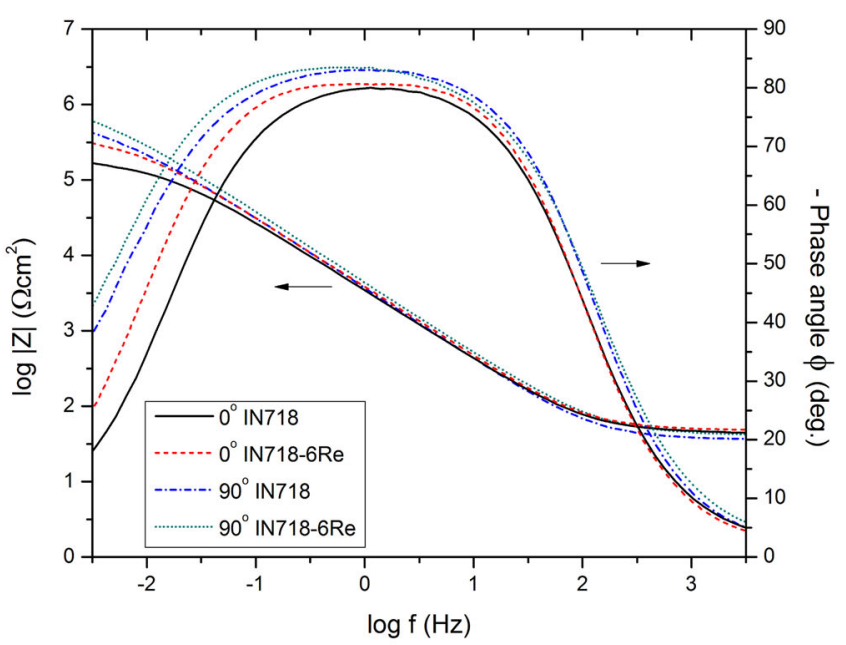

(b)

Fig. 8- (a) Nyquist and (b) Bode plots of IN718 and IN718-6Re manufactured at 0 and 90 deg exposed in $0.1 \mathrm{M} \mathrm{Na}_{2} \mathrm{SO}_{4}$ solution (pH 4). Inset in (a) shows an equivalent electrical circuit employed to fit the raw data.

Table III. Impedance Parameters of IN718 and IN718-6Re Alloys Manufactured at Two Building Orientations 0 and 90 deg Exposed in $0.1 \mathrm{M} \mathrm{Na}_{2} \mathrm{SO}_{4}$ Solution (pH 4)

\begin{tabular}{|c|c|c|c|c|c|c|c|c|}
\hline Material (Orientation) & $\begin{array}{c}R_{\mathrm{s}} \\
\left(\Omega \mathrm{cm}^{2}\right)\end{array}$ & $\begin{array}{c}R_{1} \\
\left(\mathrm{k} \Omega \mathrm{cm}^{2}\right)\end{array}$ & $\begin{array}{c}C P E_{1} \\
\left(\mu \mathrm{F} \mathrm{cm}{ }^{-2} \mathrm{~s}^{1-\mathrm{n}}\right)\end{array}$ & $n_{1}$ & $\begin{array}{c}R_{2} \\
\left(\mathrm{k} \Omega \mathrm{cm}^{2}\right)\end{array}$ & $\begin{array}{c}C P E_{2} \\
\left(\mu \mathrm{F} \mathrm{cm}{ }^{-2} \mathrm{~s}^{1-\mathrm{n}}\right)\end{array}$ & $n_{2}$ & $R_{\mathrm{p}}\left(\mathrm{k} \Omega \mathrm{cm}^{2}\right)$ \\
\hline IN718 (0 deg) & 40 & 148 & 55 & 0.91 & 29 & 558 & 0.90 & 177 \\
\hline IN718-6Re $(0 \mathrm{deg})$ & 41 & 302 & 51 & 0.91 & 37 & 789 & 0.97 & 339 \\
\hline IN718 (90 deg) & 38 & 433 & 48 & 0.94 & 228 & 152 & 0.97 & 661 \\
\hline IN718-6Re (90 deg) & 40 & 710 & 40 & 0.94 & 314 & 135 & 0.98 & 1024 \\
\hline
\end{tabular}

time constants with high coincidence can be seen. The broader phase angle peaks are also evident for samples manufactured at $90 \mathrm{deg}$.

Corrosion resistance of all tested samples can also be evaluated by the polarization resistance $R_{\mathrm{p}}$ which is inversely proportional to the corrosion rate. ${ }^{[49,50]}$ It is defined here as $R_{\mathrm{p}}=R_{1}+R_{2}$. The analysis of $R_{\mathrm{p}}$ values (Table III) shows that the corrosion resistance increases in the following order: 0 deg IN718 $<0$ deg IN718-6Re $<90$ deg IN718 < 90 deg IN718-6Re. The higher corrosion resistance of samples manufactured at $90 \mathrm{deg}$ is associated with the one order of magnitude higher value of $R_{2}$ which refers to the resistance of oxide layer in the overlapping areas. It has been shown that $R_{2}$ is inversely proportional to surface area undergoing corrosion. ${ }^{[51]}$ Thus, the lower value of $R_{2}$ observed for samples manufactured at $0 \mathrm{deg}$ indicates the greater surface area undergoing corrosion. This is consistent with the microstructure observations (Figure 3). In the case of 0 deg samples, the corroded surface corresponds to the XZ plane which exhibits a higher number of overlapping areas than the XY plane (90 deg samples). This result also confirms that the overlapping areas are the preferential sites for corrosion of investigated SLM-processed IN718-Re alloys.

The enhanced corrosion resistance of samples manufactured at 90 deg can also be inferred from the changes of the parameter $n$. This is an empirical exponent between 0 and 1 which describes the corrosion process (the higher the value, the more homogeneous the process). When $n=1$, the CPE is a pure capacitor with a perfectly smooth surface, whereas $n=0$ represents a resistor. ${ }^{[52]}$ The high values of parameter $n$ (Table III) demonstrate that all tested samples are in the passive state with high corrosion resistance. However, the higher $n$ values for 90 deg samples with respect to 0 deg samples indicate that the corrosion process occurs more homogeneously for $90 \mathrm{deg}$ samples and the oxide layer formed on their surface exhibits higher durability.

Moreover, the EIS measurements confirm the positive effect of Re addition on the corrosion resistance of IN718 alloy. This can be inferred from the changes of the polarization resistance $R_{\mathrm{p}}$ (Table III) which increases due to $6 \mathrm{wt}$ pct $\mathrm{Re}$ addition from 177 to 339 $\mathrm{k} \Omega \mathrm{cm}^{2}$ for samples manufactured at 0 deg and from 661 to $1024 \mathrm{k} \Omega \mathrm{cm}^{2}$ for 90 deg samples.

\section{CONCLUSIONS}

In the present study, the effect of rhenium addition on microstructure and corrosion resistance of the SLM-processed IN718 alloy is investigated. The main conclusions can be summarized as follows:

1. The microstructure of as-built IN718-Re alloys predominantly consists of columnar grains growing across several layers parallel to the building 
direction. Each columnar grain is characterized by the fine columnar/cellular dendritic substructure. The interdendritic spaces are highly enriched in $\mathrm{Nb}$ and Mo which results in the formation of Laves phases and MC-type carbides between dendritic cells.

2. Rhenium addition tends to segregate to $\gamma$ phase dendrites and leads to the change of columnar/cellular dendrites size. The width of columnar/cellular structures increases with increasing Re content from $893 \pm 223$ to $1936 \pm 515 \mathrm{~nm}$ observed for IN718 and IN718-6Re, respectively.

3. The potentiodynamic polarization tests show that the $\mathrm{Re}$ addition results in the enhanced corrosion resistance of IN718 alloy in $0.1 \mathrm{M} \mathrm{Na}_{2} \mathrm{SO}_{4}$ and $\mathrm{NaCl}$ solutions ( $\mathrm{pH} 4$ ). The corrosion current density is significantly reduced for IN718-Re alloys, whereas the corrosion potential is shifted to more positive values with increasing Re content.

4. The corrosion resistance of IN718-Re alloys has been also investigated with respect to the building orientation. Samples manufactured at $90 \mathrm{deg}$ (XY plane) possess better corrosion resistance than those fabricated at $0 \mathrm{deg}$ (XZ plane). It is caused by the higher fraction of laser overlapping areas observed for the $\mathrm{XZ}$ plane which seem to be the preferential sites for corrosion of investigated SLM-processed IN718-Re alloys.

\section{ACKNOWLEDGMENTS}

This research was financially supported by the National Centre for Research and Development (No. PBS1/A5/12/2012). Authors would like to thank Dr. G. Cieślak from Warsaw University of Technology, Faculty of Materials Science and Engineering for conducting XRF measurements.

\section{OPEN ACCESS}

This article is distributed under the terms of the Creative Commons Attribution 4.0 International License (http://creativecommons.org/licenses/by/4.0/), which permits unrestricted use, distribution, and reproduction in any medium, provided you give appropriate credit to the original author(s) and the source, provide a link to the Creative Commons license, and indicate if changes were made.

\section{REFERENCES}

1. X. Wu: Mater. Sci. Technol., 2007, vol. 23, pp. 631-40.

2. K. Osakada and M. Shiomi: Int. J. Mach. Tools Manuf., 2006, vol. 46, pp. 1188-93.

3. J.-P. Kruth, G. Levy, F. Klocke, and T.H.C. Childs: CIRP Ann. Manuf. Technol., 2007, vol. 56, pp. 730-59.

4. T. Kurzynowski, E. Chlebus, B. Kuźnicka, and J. Reiner: Proc. SPIE 8239, High Power Laser Mater. Process. Lasers, Beam Deliv. Diagnostics, Appl., 2012, p. 823914.
5. G.N. Levy, R. Schindel, and J.P. Kruth: CIRP Ann. Manuf. Technol., 2003, vol. 52, pp. 589-609.

6. E. Chlebus, K. Gruber, B. Kuźnicka, J. Kurzac, and T. Kurzynowski: Mater. Sci. Eng. A, 2015, vol. 639, pp. 647-55.

7. J. Choi, G. Shin, S. Yang, D. Yang, J. Lee, M. Brochu, and J.-H. Yu: Powder Technol., 2017, vol. 310, pp. 60-66.

8. W.M. Tucho, P. Cuvillier, A. Sjolyst-Kverneland, and V. Hansen: Mater. Sci. Eng. A, 2017, vol. 689, pp. 220-32.

9. D. Zhang, W. Niu, X. Cao, and Z. Liu: Mater. Sci. Eng. A, 2015, vol. 644 , pp. 32-40.

10. T. Brynk, Z. Pakiela, K. Ludwichowska, B. Romelczyk, R.M. Molak, M. Plocinska, J. Kurzac, T. Kurzynowski, and E. Chlebus: Mater. Sci. Eng. A, 2017, vol. 698, pp. 289-301.

11. K.N. Amato, S.M. Gaytan, L.E. Murr, E. Martinez, P.W. Shindo, J. Hernandez, S. Collins, and F. Medina: Acta Mater., 2012, vol. 60, pp. 2229-39.

12. Z. Wang, K. Guan, M. Gao, X. Li, X. Chen, and X. Zeng: $J$. Alloys Compd., 2012, vol. 513, pp. 518-23.

13. N. Nadammal, S. Cabeza, T. Mishurova, T. Thiede, A. Kromm, C. Seyfert, L. Farahbod, C. Haberland, J. Schneider, P. Portella, and G. Bruno: Mater. Des., 2017, vol. 134, pp. 139-50.

14. M.E. Aydinöz, F. Brenne, M. Schaper, C. Schaak, W. Tillmann, J. Nellesen, and T. Niendorf: Mater. Sci. Eng. A, 2016, vol. 669, pp. 246-58.

15. M.D. Sangid, T.A. Book, D. Naragani, J. Rotella, P. Ravi, A. Finch, P. Kenesei, J.S. Park, H. Sharma, J. Almer, and X. Xiao: Addit. Manuf., 2018, vol. 22, pp. 479-96.

16. J. Schneider, B. Lund, and M. Fullen: Addit. Manuf., 2018, vol. 21, pp. $248-54$.

17. T.D. McLouth, G.E. Bean, D.B. Witkin, S.D. Sitzman, P.M. Adams, D.N. Patel, W. Park, J.M. Yang, and R.J. Zaldivar: Mater. Des., 2018, vol. 149, pp. 205-13.

18. J.R. Davis: ASM Specialty Handbook: Nickel, Cobalt, and Their Alloys, ASM International, Materials Park, Ohio, 2000, pp. 1-188.

19. B.B. Rashmi, A. Collins, and S. Silverman: in Superalloys 718 , 625, 706 and Various Derivatives, E.A. Lorin, ed., TMS, Warrendale, PA, 2001, pp. 47-55.

20. T.M. Pollock and S. Tin: J. Propuls. Power, 2006, vol. 22, pp. $361-74$.

21. A. Naor, N. Eliaz, E. Gileadi, and S.R. Taylor: AMMTIAC $Q$., 2010, vol. 5, pp. 11-14.

22. S. Wöllmer, T. Mack, and U. Glatzel: Mater. Sci. Eng. A, 2001, vols. 319-321, pp. 792-95.

23. D. Blavette, P. Caron, and T. Khan: Scr. Metall., 1986, vol. 20, pp. 1395-1400.

24. M. Karunaratne, P. Carter, and R.C. Reed: Mater. Sci. Eng. A, 2000, vol. 281, pp. 229-33.

25. A. Janotti, M. Krčmar, C.L. Fu, and R.C. Reed: Phys. Rev. Lett., 2004, vol. 92, p. 85901.

26. A. Volek, F. Pyczak, R.F. Singer, and H. Mughrabi: Scr. Mater., 2005, vol. 52, pp. 141-45.

27. P.J. Warren, A. Cerezo, and G.D.W. Smith: Mater. Sci. Eng. A, 1998, vol. 250, pp. 88-92.

28. U. Hemmersmeier and M. Feller-Kniepmeier: Mater. Sci. Eng. A, 1998, vol. 248, pp. 87-97.

29. A.F. Giamei and D.L. Anton: Metall. Trans. A, 1985, vol. 16A, pp. 1997-2005.

30. T. Jin, W.Z. Wang, X.F. Sun, and Z.Q. Hu: Mater. Sci. Forum, 2010, vols. 638-642, pp. 2257-62.

31. Z. Zhu, H. Basoalto, N. Warnken, and R.C. Reed: Acta Mater., 2012, vol. 60, pp. 4888-4900.

32. M.A. Amin, N. El-bagoury, M. Saracoglu, and M. Ramadan: Int. J. Electrochem. Sci., 2014, vol. 9, pp. 5352-74.

33. T. Kurzynowski, I. Smolina, K. Kobiela, B. Kuźnicka, and E. Chlebus: Mater. Des., 2017, vol. 132, pp. 349-59.

34. L. Thijs, M.L.M. Sistiaga, R. Wauthle, Q. Xie, J.-P. Kruth, and J. Van Humbeeck: Acta Mater., 2013, vol. 61, pp. 4657-68.

35. L.L. Parimi, G.A. Ravi, D. Clark, and M.M. Attallah: Mater. Charact., 2014, vol. 89, pp. 102-11.

36. T. Antonsson and H. Fredriksson: Metall. Mater. Trans. B, 2005, vol. 36B, pp. 85-96.

37. J.N. Dupont, C.V. Robino, J.R. Michael, M.R. Notis, and A.R. Marder: Metall. Mater. Trans. A, 1998, vol. 29A, pp. 2785-96.

38. J.N. Dupont, C.V. Robino, and A.R. Marder: Acta Mater., 1998, vol. 46, pp. 4781-90. 
39. M.J. Cieslak, T.J. Headley, G.A. Knorovsky, A.D. Romig, and T. Kollie: Metall. Mater. Trans. A, 1990, vol. 21A, pp. 479-88.

40. N. El-Bagoury, K. Yamamoto, H. Miyahara, and K. Ogi: Mater. Trans., 2005, vol. 46, pp. 909-15.

41. N. El-Bagoury, A.A. Omar, and K. Ogi: Metallogr. Microstruct. Anal., 2012, vol. 1, pp. 35-44.

42. T. Vilaro, C. Colin, J.D. Bartout, L. Naze, and M. Sennour: Mater. Sci. Eng. A, 2012, vol. 534, pp. 446-51.

43. A.A. Antonysamy: Ph.D. Thesis, University of Manchester, UK, 2012.

44. P.A. Kobryn and S.L. Semiatin: J. Mater. Process. Technol., 2003, vol. 135 , pp. $330-39$.

45. A.M. Riley, D.B. Wells, and D.E. Williams: Corros. Sci., 1991, vol. 32 , pp. $1307-13$.
46. S. Al Saadi, Y. Yi, P. Cho, C. Jang, and P. Beeley: Corros. Sci., 2016, vol. 111, pp. 720-27.

47. U. Trdan and J. Grum: Corros. Sci., 2014, vol. 82, pp. 32838.

48. D. Karthik, S.A.X. Stango, U. Vijayalakshmi, and S. Swaroop: Surf. Coatings Technol., 2017, vol. 311, pp. 46-54.

49. J. Zhang, C. Gu, and J. Tu: Surf. Coatings Technol., 2017, vol. 320, pp. $640-47$.

50. T. Chen, H. John, J. Xu, Q. Lu, J. Hawk, and X. Liu: Corros. Sci., 2014, vol. 78, pp. 151-61.

51. Z. Brytan, J. Niagaj, and L. Reiman: Appl. Surf. Sci., 2016, vol. 388 , pp. $160-68$.

52. J.R. MacDonald: J. Electroanal. Chem. Interfacial Electrochem., 1987, vol. 223, pp. $25-50$. 